\title{
Inmate carrier of cutis verticis gyrata
}

\author{
Martínez-Carpio PA ${ }^{1,2}$, Formigón Roig M³, Matas Marín S ${ }^{1}$, Aranda Sánchez A', \\ Bedoya del Campillo $\mathrm{A}^{2}$
}

${ }^{1}$ Prison Primary Health Care Team of La Roca del Vallès-1. Catalonian Institute of Health. Regional
Government of Catalonia. Quatre Camins Prison. La Roca del Vallès. Barcelona.
${ }^{2}$ Prison Primary Health Care Team of La Roca del Vallès-2. Catalonian Institute of Health. Regional
Government of Catalonia. Quatre Camins Prison. La Roca del Vallès. Barcelona.
${ }^{3}$ Dermatology Unit. Hospital Consorci Sanitari de Terrassa. Barcelona.

\begin{abstract}
The cutis verticis gyrata (CVG) is a clinical stigma considered to be very rare that mostly affects males. It consists of characteristic folds in the scalp, similar to cerebral convolutions, which tend to affect the parietal and occipital areas. It is considered a pachyderma of the cranial skin, and can appear at different ages for different reasons. Images are shown of the first clinical case described in prisons, as well as the initial diagnostic and therapeutic approach.
\end{abstract}

Keywords: scalp, diagnosis, general practice, prisons.

Text received: 26/06/2018

Text accepted: 28/06/2018

\section{INTRODUCTION}

Cutis verticis gyrata is a little known sign, condition, clinical stigma or disease that is regarded as very rare that affects mostly males. It consists of folds in the scalp that look similar to the folds of the brain. The extent, shape and thickness may vary and it appears in the parietal and occipital areas of the scalp. The skin and subcutaneous tissue of the cranium thicken and copy the shape of the brain surface, which is why it has received other names, now no longer used, such as pachydermie vorticellee, cerebriform deformity, cutis sulcata, bulldog scalp or cutis capitis strata ${ }^{1-8}$.

The prevalence of the disease is unknown, but it is estimated that it affects $1 / 100,000$ men and $0.26 / 100,000$ women in the general population ${ }^{1,4,5}$. Regardless of the appearance and location of the cerebriform ridges, the consensus is that there are three different forms of CVG, each with a different degree of severity, prognosis and management:

- CVG primary essential.

- CVG primary non essential.

- $\mathrm{CVG}$ secondary ${ }^{1-8}$.
The aetiology is considered to be idiopathic or essential (CVG primary essential) when it is not associated with any other pathology $y^{2-5}$. In such essential cases, no malignant disruption has been reported, and the only problem may be an aesthetic one. The cases of CVG primary non essential are much more frequent and are the ones associated with neurological and ophthalmologic conditions, especially severe mental retardation, intracranial brain disorders, convulsions, cerebral palsy, strabismus, cataracts or blindness ${ }^{1,3,8}$. Finally, the cases of CVG secondary (occasionally reversible) have not been very well clarified and have become a "catch all", where there is confusion between associations and different causes (pachydermoperiostosis, cerebriform intradermal nevus, liver disorders, hamartomas, neurofibromas, dermatosis of the scalp, psoriasis, tumours, hypergammaglobulinemia inmunoglobulina $\mathrm{E}$ ( $\mathrm{IgE}$ ), endocrine disruption, syphilis, acromegalia, amiloidosis, cretinism, diabetes mellitus, fragile $\mathrm{X}$ chromosome syndrome, Ehlers-Danlos syndrome, Graves' disease, Turner's syndrome and a wide range of chromosome disorders ${ }^{1-8}$. 
This study reports the first case of a patient carrying CVG in prison. The objective is to make this sign, problem or entity more public, describe initial management in consultation and establish the complementary examinations required to diagnose the sub-type, the prognosis and the therapeutic approach.

\section{MATERIALS AND METHODS}

\section{Clinical case}

The patient was a black male of 28 years of age, native of Gambia, who was an inmate in module VII of the prison of Cuatre Camins (La Roca del Vallès, Barcelona). He came to the medical consultation saying that a series of sizeable cerebriform-shaped skin deformities had suddenly appeared on his head in the area of the crown, without any traumatic precedents (Figure 1). The patient was surprised when he came to consultation, just after having his head completely shaved, after being advised to do so by the inmate who had shaved him, and the patient affirmed that previously he did not have the deformities, although he had never completely shaved his head before. The wounds showed a slight inflammatory activity. The patient was immediately taken to the dermatology surgery, where after a simple inspection he was diagnosed with cutis verticis gyrata. The image is pathognomonic (Figure 1).

\section{Case history, physical examination and initial approach with the patient}

After diagnosis, he was once again transferred to the medical consultation of the module, where the first interview and a physical examination were carried out, with no significant results. The patient was informed in a simple and understandable manner that a series of complementary examinations were necessary in order to find out the prognosis and treatment. He stated that he was willing to undergo the specific examinations to establish the case, signing the corresponding informed consent and authorisation to transmit his images for scientific and research purposes. He was informed that he had probably had the problem for some time and that it might not disappear on its own.

Given the likelihood of CVG secondary, which could respond positively to corticosteroids, a treatment was recommended with $30 \mathrm{mg}$ of prednisone after breakfast for ten days, and another followup appointment when the treatment ended. He was advised to let his hair grow back to hide the defect if he felt more comfortable that way.

\section{Additional examinations}

To categorise the CVG for prognostic and therapeutic purposes, the following additional diagnostic tests and consultations were programmed, based on the recommendations of other authors ${ }^{1-8}$ :

- Basic blood analysis, serology for hepatitis, syphilis and human immunodeficiency virus (HIV), hormone tests (growth hormone, thyroid function, androgens, oestrogens), tumour markers (carcinoembryonic antigen and alphaprotein), inflammation markers (erythrocyte sedimentation rate; $\mathrm{C}$-reactive protein) and $\operatorname{IgE}$ analysis.

- Radiography of cranium, chest and right forearmhand, to test for possible parenchymal lung lesions, bone anomalies or possible periosteosis.

- Computerised axial tomography (CAT) of cranium without contrast, to rule out possible intracranial lesions.

- Biopsy of skin lesion, to rule out secondary causes and find out the anatomo-pathological nature of the lesion.

- Genetic laboratory study, to determine possible altered genes associated with the diagnosis and prognosis.

- Consultation with clinical psychology, to establish the IQ, and a neuropsychological analysis and personality study.

- Consultation with psychiatry, to rule out possible severe psychiatric illnesses that do not appear in current diagnoses.

\section{RESULTS}

The results of the complementary examinations have not been completed, they are being researched at this moment in time, and should determine the final diagnosis. However, the available data ten days after commencing treatment with prednisone, and the data from the physical examination already give indications as to the directions the diagnosis should take (Figures 2 and 3 ).

\section{Case history after ten days and satisfaction with the treatment}

The patient said that he had greatly improved. He asked only for the treatment to be continued so as to finally eliminate all the bumps and protrusions 


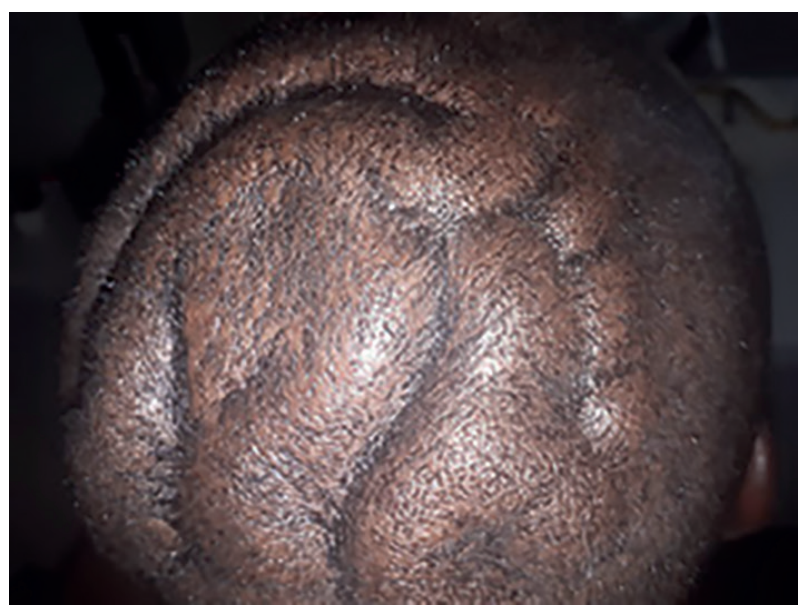

Figure 1. Characteristic image of cutis verticis gyrata (CVG) that shows the skin deformity (pachyderma), which takes a cerebriform shape, with folds and convolutions. Superior-posterior view of cranium.

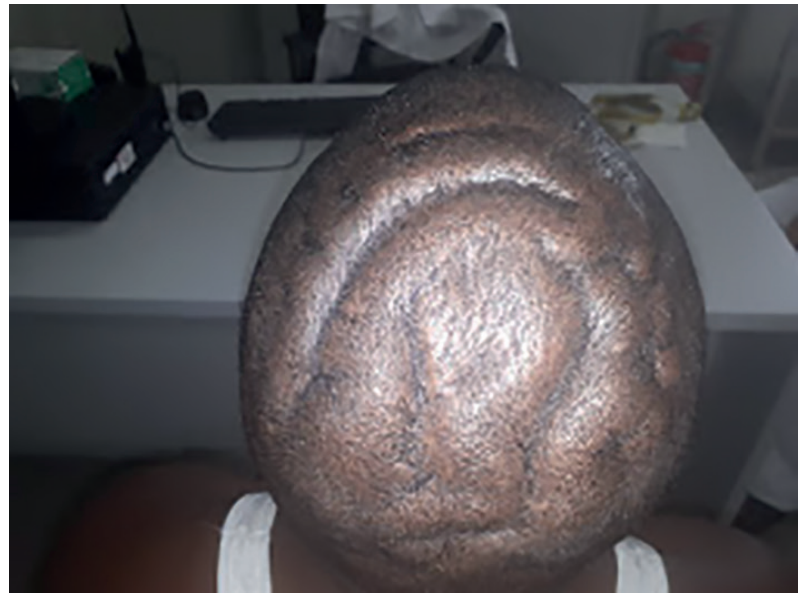

Figure 2. Cutis verticis gyrata (CVG) after ten days of treatment with prednisone $30 \mathrm{mg} /$ day. Superior-posterior view of cranium.

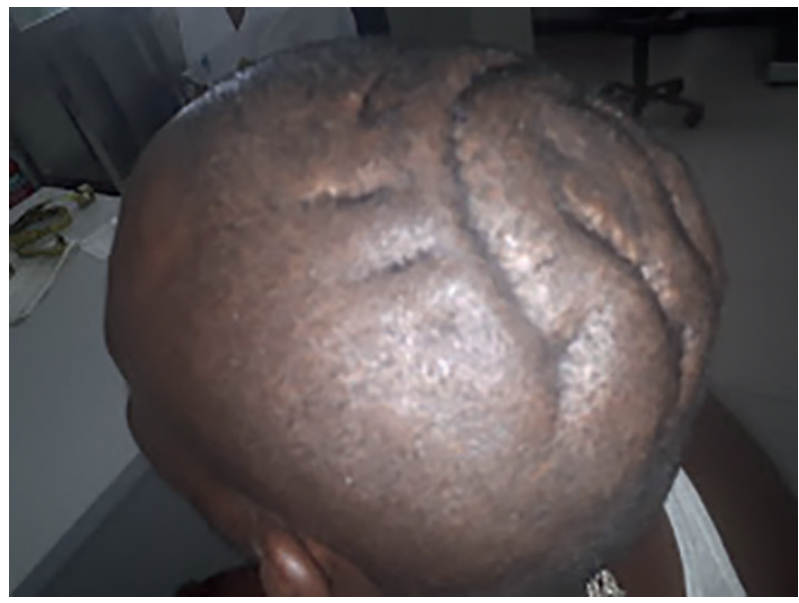

Figure 3. Cutis verticis gyrata (CVG) after ten days of treatment with prednisone $30 \mathrm{mg} /$ day. Left posterolateral view of cranium. that, according to him, had "suddenly" appeared, as he stated at the beginning, and now he stated he may have noticed something, but that he never imagined it was something like that. When they asked him about the symptoms, he made no mention of joint pains, breathing difficulties, stomach pains or signs of any other kind. He was solely concerned about the visual and distinguishing aspects of the problem.

The treatment with prednisone may have somewhat reduced the volume of the protrusions. Perhaps, they appeared to be less marked when using photographic comparisons, but without any really significant changes according to our observations. For this reason the treatment was interrupted. However, the patient repeated that he had noticed a major improvement and that the "lumps" (pachyderma) were notably smaller. The steroid treatment was terminated in descending order over one week and no other medication was prescribed (Figures 2 and 3).

The question was again asked if he noticed lumps or ridges when he had long hair, or if the scalp bothered him or itched, since these symptoms are common in $\mathrm{CVG}^{1,2,6}$. He said that ha was not aware of having any lesions, and this time he admitted that he had shaved his head 5 or 6 years previously and that then there was no visible anomaly. He did not know of any similar cases in his family or amongst his siblings. He had never noticed any irritations, stinging or discomfort in the zone, given that he was practically unaware of the lesion because he had long hair.

\section{Details of the inspection and examination at ten days}

He presented in good general condition, blood pressure of 140/80, muscular and with no notable anthropometric parameters: height $=170 \mathrm{~cm}$, weight $=82 \mathrm{~kg}$, body mass index $(\mathrm{BMI})=28.37 \mathrm{~kg} / \mathrm{m}^{2}$, cranial perimeter (transversal greater in the eyebrow area) $=58 \mathrm{~cm}$, largest perimeter of chest (when inhaling $=111 \mathrm{~cm}$, waist perimeter $(1 \mathrm{~cm}$ above navel $)=$ $86 \mathrm{~cm}$, perimeter of hips (in area of trochanters) $=98$ $\mathrm{cm}$, waist-hips index $(\mathrm{WHI})=0.88$.

In the consultation he showed himself to be of apparently normal intelligence, with fluid and coherent speech, with no psychotic, aggressive or impulsive traces, collaborative, polite and grateful to the medical staff, because he understood that they were trying to help him. He did not present any neurological alterations or evident mental retardation. There was no background of epilepsy. He did not present any dysmorphic facial features, or pachyderma on his face, or squints, or abnormal angles in the eyes. 
The skin was oily in appearance, with perspiration and a number of keloids on both ears. Hands and feet showed no signs of acromegaly, but there was slight brachydactyly, incipient nail clubbing and thickening of the skin of the fingers. Inspection of the oral cavity showed no notable anomalies (without macroglossia); heart and lung auscultation showed no abnormal sounds, and there were no significant findings in the neurological and other examinations.

\section{DISCUSSION}

It was found in Sweden in the 1960s that the prevalence of CVG in institutions for the mentally deficient was thousands of times higher than amongst the general public. It was found that most of the persons affected had an IQ of less than 35 , and that only 38 of the cases were women. An increased incidence of convulsions and eye defects in carriers of CVG was also reported $^{9,10}$. More recently, Hernández et al. published a study showing that the prevalence of CVG in a male psychiatric institution in Colombia is 5.9\% (65 cases out of 1,100 institutionalised $)^{8}$. The most frequent diagnoses was behavioural disorder (46\% of cases), followed by impulse control disorder and schizophrenia (percentages not shown). If this study is analysed in greater depth, it can be seen that the information is confused and does allow any conclusions to be drawn other than the confirmation that most of the cases of CVG could be related to severe neuro-psychiatric conditions ${ }^{8}$. The fact that there are many more male inmates in prison, along with the fact that the neuro-psychiatric disorder is also much more prevalent, highlights the potential interest that this rare problem has in such a setting.

This is the first case of CVG described in prisons, in a patient who does not show any neuro-psychiatric disorders or any severe psychiatric illness. The preliminary results available at this moment in time (pending complementary explorations) indicate a possible case of primary pachydermoperiostosis (TouraineSolente-Golés syndrome). In the review of the histories of previous cases that have been published, it can be seen that some patients labelled with CVG primary essential could correspond to incomplete forms of this very rare disease characterised by pachyderma, periostosis and nail clubbing ${ }^{1}$.

If the hair covers a large part of the defect and it is not a major aesthetic problem, the treatment for CVG is good hygiene when washing the hair, rubbing shampoo into the folds to eliminate residues and dirt. In patients with very pronounced defects, plastic surgery to improve the person's appearance may be proposed ${ }^{2}$.

\section{CONCLUSION}

The diagnosis of CVG is by simple inspection, because all the images published are very similar to the ones shown here, pathognomonic of this strange condition. Such a diagnosis is impossible when the characteristics of the lesion are unknown, but very simple once the images provided are seen. There are no agreed protocols or guides for these cases, and so the approach presented may help in advancing towards a better classification of the different cases, with more data and better knowledge of this defect.

\section{CORRESPONDENCE}

Pedro A. Martínez-Carpio

Centro Penitenciario Quatre Camins.

EAPP-La Roca del Vallès-1.

Institut Català de la Salut.

Carretera de Masnou a Granollers. Km 13,425

08430 La Roca del Vallès. Barcelona.

E-mail: pmc@investilaser.com

\section{REFERENCES}

1. Ferrari B, Abad ME, Larralde M. Cutis verticis gyrata. Educación Médica Continua. Dermatol Argent. 2014;20:157-63.

2. Ennounhi M, Gherrouani A, Moussaoui A. Idiopathic Cutis Verticis Gyrata in a female. Cureus. 2015;10:e2015.

3. Schenato LK, Gil T, Carvalho LA, Ricachnevsky N, Sanseverino A, Halpern R. Cutis verticis gyrata primária esencial. J Pediatr (Rio J). 2002;78:7580.

4. Sigüenza NL, Amaya AG, Yépez PE, Peña SJ, Ayala MP. Caso clínico: Cutis Gyrata Vertis. Arch Venez Farmacol Clin Ter. 2017;36:97-100.

5. Hurtado PM, Pachajoa H. Imágenes en Medicina: Cutis Verticis Gyrata. Medicina (Buenos Aires). 2012;72:132.

6. Goncalves MI, López M, Franco F, Zamora M, Correa J, Jaramillo S. Cutis Verticis Gyrata: A propósito de un caso. Dermatol Venez. 2014;52:29-32.

7. Kosumi H, Izumi K, Natsuga K, Yamaguchi Y, Itami A, Shimizu H. Cutis Verticis Gyrata fluc- 
Martínez-Carpio PA, Formigón Roig M, Matas Marín S, Aranda Sánchez A, Bedoya del Campillo A.

Inmate carrier of cutis verticis gyrata.

tuation with atopic dermatitis disease activity. Acta Derm Venereol. 2017;97:1245-6.

8. Hernández JF, Espejo LM, Correa RL, de la Espriella R. Cutis verticis gyrata en población masculina institucionalizada con enfermedad mental crónica en Colombia. Serie de casos. Acta Neurol Colomb. 2015;31:404-11.
9. Akesson HO. Cutis verticis gyrata and mental deficiency in Sweeden I. Epidemiologic and clinical aspects. Acta Med Scand. 1964;175:115-27.

10. Akesson HO. Cutis verticis gyrata and mental deficiency in Sweeden II. Genetic aspects. Acta Med Scand. 1965;177:459-64. 